\title{
Hierarchical Facility Location Model for allocating cancer treatment units in interior of Rio de Janeiro
}

\author{
Isabella Fischer Guindani Vieira ${ }^{\mathrm{a} *}$ (D), Matheus Ferreira de Barros $^{\mathrm{b}}$ (D), Allan Cormack $^{\mathrm{a}, \mathrm{b}}$ (1) \\ aPontifícia Universidade Católica do Rio de Janeiro, Rio de Janeiro, RJ, Brasil \\ bUniversidade Federal do Rio de Janeiro, Rio de Janeiro, RJ, Brasil \\ *if@aluno.puc-rio.br
}

\begin{abstract}
Paper aims: This work aims at proposing a mathematical model for allocation of oncological treatment units of SUS.

Originality: A model of the same architecture was not found in the literature for the delimited problem.

Research method: The mathematical models of location in the literature were reviewed and based the choice by the two-level hierarchical pq-median model with additional constraints of maximum distance and vertices eligibility, which was implemented in the CPLEX optimization software.
\end{abstract}

Main findings: Satisfactory results with homogeneous networks, centralized facilities in their service area and shorter distance traveled by users indicate the efficiency of the model in determining the optimum location given the number of facilities to be allocated.

Implications for theory and practice: The model proved to be an efficient tool to assist health managers in their decision-making about the network of facilities, not just oncological, but of any nature and many others public sectors. Keywords

Facility location problems. Integer programming. Oncology.

How to cite this article: Vieira, I. F. G., Barros, M. F., \& Cormack, A. (2019). Hierarchical Facility Location Model for allocating cancer treatment units in interior of Rio de Janeiro. Production, 29, e20190026. https://doi.org/10.1590/01036513.20190026.

Received: Mar. 31, 2019; Accepted: Aug. 12, 2019.

\section{Introduction}

The central objective of a National Health Service (NHS) is to provide universal and free healthcare and medicines for all citizens. This system is financed through taxes and the general budget of the State. In Brazil, this model has been adopted since 1990 with the creation of the Unified Health System (SUS), in accordance with article 198 of the Federal Constitution of 1988 (Brasil, 1988).

However, by reducing the scale for the units of the federation, failures in the system are observed that go against the right of the citizen. Especially in the State of Rio de Janeiro (ERJ), the quality of service provided to the population appears to contradict the doctrinal principles of SUS. At the end of 2017, the Regional Council of Medicine announced the state of technical calamity in the health area in the state due to problems such as lack of medicines and personnel, delays in salaries and broken equipment, calling society's attention to the real bankruptcy of the structure public health system. This is justified by the report entitled Impact Assessment and Data Openness in Planning and Financial Health Management, produced by the Public Prosecutor's Office of Rio de Janeiro in March of this year, which shows that at least since 2014, the ERJ has stopped applying the minimum of $12 \%$ of annual tax revenue in public health actions and services. The complaint also covers aspects relating to transparency. According to him, the State Government does not keep the data of the Transparency Portal up to date, clear and with easy access, being in the last position in the ranking of the Brazil Transparente scale. 
The same deficiency in demonstrating financial data exists in relation to the provision of services. The databases searched in this study, which should show how many procedures of any kind were performed by the public network in a given period, such as several of the systems available by DATASUS, the National Demographic and Health Survey (PNDS) and the Cancer Registry of Population Base (RCBP) in Instituto Nacional de Câncer José Alencar Gomes da Silva (2018b), are mostly outdated and with missing or inconsistent information. Despite the lack of data, the low rate of user satisfaction makes it possible to infer that actions, efforts and strategic initiatives can be structured and designed to serve the collective good of the population. It is important to note that this article is an extended version of what was held at the 2018 POMS International Conference in Rio and its further publication (Leiras et al., 2019). In the current version, both the literature review and the discussion of the results have been done more broadly and consistently.

\section{Oncology's outlook}

As mentioned in the Clinical Protocols and Therapeutic Guidelines on Oncology, published by the Ministry of Health in 2014, oncology is one of the most deprived medical specialties of large clinical trials, due to many factors complicating the disease itself. It is often due to the rarity of the clinical condition, others due to its severity, which imposes the need for rapid responses, or because of the presence of multiple comorbidities or different stages of neoplastic evolution.

According to Ford \& Mitchell (2000), the lack of adequate treatment causes the various types of cancer to become invasive, metastatic, that is, they progress to other parts of the body, and lead to the death of the individual with the disease. Even with the advancement of technology, with the various forms of treatment available, disease control and prevention are unquestionably the most effective way to minimize the problems brought to bearer. It is emphasized here that cancer treatment can be performed through surgery, radiotherapy, chemotherapy, hormone therapy and bone marrow transplantation, either alone or by combining more than one modality.

Cancer today is the second largest cause of death in Brazil, according to data from the Mortality Information System (SIM) for 2016, the most current year available. According Lisboa (2014) as a result of industrialization, people today are exposed to a variety of risk factors such as unhealthy working environment, malnutrition and exposure to chemical and carcinogenic agents. For the biennium 2018-2019, it was estimated by the INCA (Instituto Nacional de Câncer José Alencar Gomes da Silva, 2017) that there will be approximately 582 thousand new cases in the country and points out that the number of cases is increasing each year, as well as the severity of the disease in the first diagnosis, and the growth of mortality caused by cancer occurs not only in Brazil but throughout the world. According to the American Cancer Society (2018), the number of new cases worldwide will rise from 13.2 million to 21.6 million a year between 2010 and 2030. Looking at the financial aspects, this increase means that cancer treatment costs worldwide will increase from $\$ 290$ to $\$ 458$ billion over the same period.

Therefore, it is noted the need to rethink the structure of cancer care in the SUS to meet the growing demand, diagnosed with more advanced stages of the disease, especially for the state of Rio de Janeiro, where the sector is already deficient. In the state the statistical control of the disease appears even more inefficient. The two Population-Based Cancer Registries in Rio de Janeiro and Angra dos Reis were inoperative until the last years. At present, the Angra dos Reis unit is active, but only updating the databases with the passed data. The Hospital Registry of Cancer, accessed in June 2018, presents a delay of three years of data, considering that the last available year does not have data from most hospitals and centers.

According to INCA, the state has 27 cancer treatment units and centers distributed in only 11 cities, of which only 4 belong to the interior of the state, which will be the target of this study. This shows that patients in areas not covered by the service they need to travel long distances, many times superior than 200 kilomiters, or they have to accept to get treatment at a nearer facility even if it can not offer the most recommended treatment for its pathology.

\section{Objectives}

The present work proposes to carry out a bibliographic survey about the studies of Localization Problems, specifically the hierarchical model based on medians, applied to Health and Oncology. Based on the acquired knowledge, it's possible to perform the selection and adequacy of a mathematical model for facilities location to the determination of an ideal network of oncological units in the interior of the State of Rio de Janeiro. Also, its computational implementation for different scenarios with different assigned values to the parameter $\mathrm{P}$, so 
that the variation of the results acts as a sensitivity analysis and allows the evaluation of the optimal location model for the cancer care units from the computational results as a tool to support health management.

\section{Literature review}

A relevant research line of Operational Research involves the applications of the Facility Location Problems. The importance of location studies is attributed by Ballou (2001) to the high impacts that decisions of this nature exert on logistics costs, since they involve high investments. The analysis of possible location alternatives is essential for consistent decision making on the geographic position of an operation.

In health systems planning, facility location models have often been used as decision support tools, as described by Daskin \& Dean (2004), but few of these studies comprehend the diagnosis and treatment of cancer, such as can be observed throught the search for similar work conduced at the Scopus and Web of Science databases (Table 1).

Table 1. Number of search results for keywords in Scopus and Web of Science databases.

\begin{tabular}{|c|c|c|c|}
\hline Component & Search terms & Scopus & WoS \\
\hline Method $[A]$ & $\begin{array}{l}\text { [hierarchical location model OR hierarquical service location model OR hierarquical location } \\
\text { problem OR hierarquical facility location OR hierarchical unit location OR median-based } \\
\text { hierarchical model] }\end{array}$ & 212 & 2926 \\
\hline Method $[A]+$ Sector $[B]$ & $\begin{array}{l}\text { [A] AND [health OR health system OR health care OR public health OR public health system } \\
\text { OR health centers OR health units] }\end{array}$ & 3 & 221 \\
\hline $\begin{array}{l}\text { Method }[A]+\text { Sector }[B]+ \\
\text { Segment }[C]\end{array}$ & $\begin{array}{l}{[A] \text { AND }[B] \text { AND [oncology OR oncological OR cancer OR cancer treatment OR oncological }} \\
\text { treatment OR oncology center OR oncological center OR oncology unit OR oncological unit] }\end{array}$ & 0 & 15 \\
\hline
\end{tabular}

Source: Research conducted on April 29, 2018.

Firstly, the keywords of the group $[A]$ referring to the method used were inserted, in this case the hierarchical localization model. Given the high number of localized publications, being 212 in the Scopus database and 2926 in the Web of Science, their individual analysis would be expensive and unfeasible, and therefore the research was submitted to another filter, with keywords [B] referring to sector of the application, health systems (words [A] AND [B]). The number of results decreased considerably, but there were still many for the detailed and judicious analysis needed to fully understand the subject. Therefore, another filter was included, the words of the group [C], about the segment of oncology and treatments for cancer (search for the words [A] AND [B] AND [C]), this time resulting in a reasonable number of publications.

Of the 15 works found, none presents technical deepening in facilities location as expected. Finally, this paper presents an application of a level 2 pq-median model and its computational result, focused on the Brazilian public health reality. This modeling appears in few publications in Brazil, and still with modifications in the restrictions made by the authors, it is hoped to contribute to the knowledge in the area and stimulate researches of innovative methods that bring benefits to the common good.

\section{Facilities location in healthcare}

According to Arenales (2007), the location of facilities is a critical aspect of the strategic planning of public and private organizations. For Daskin \& Dean (2004) in the industry, poorly located facilities or the use of the inadequate facilities will result in increased expenses and/or loss of quality customer service. And even if the number of facilities is adequate, if poorly located, they will result in difficulties in meeting the demand.

According to Belfiore \& Fávero (2013), the objective of the facility location problem is to determine the number of locations and select from among a set of candidate sites those that best meet the given parameter, be it cost, time, or what is proposed. In general, location studies are concerned with studying ways to optimize the network of facilities, whether in the deployment or operation, in the face of costs, transportation time, quality of customer service, or whatever the objective of the organization. The subject was widely discussed by Ahmadi-Javid et al. (2017), Farahani et al. (2014), Drezner \& Hamacher (2002), Daskin \& Dean (2004), and applied in several contexts such as the humanitarian logistics, explored in Boonmee et al. (2017). Ortiz-Astorquiza et al. (2018) offers a wide review of Hierarchical Facility Location Models (HFLM), which is the kind of Facility Location Model that will be developed. 
Some authors have attempted to aggregate the advantages of coverage models into the p-median models by introducing a constraint that establishes a maximum feasible distance (or maximum travel time) that should not be exceeded. This concept was introduced by Toregas et al. (1971), in the context of health systems, has already been used by other authors such as Ruth (1981) and will be also approached in the present study, including the hierarchy between Facilities: it has a pq-median structure, minimizing the distance weighted by the number of users, as well as considers restrictions with the critical distances of route that should not be exceeded to confirm the fulfillment of the demand and to ensure the quality of the service.

There may be connections that differentiate the services provided to patients not served by a specific facility initially, and the allocated demand is different for each type of facility. lgnoring the relationship between levels and locating them separately would generate multiple (equal to the number of levels) sub-optimal solutions when referenced to the chosen parameter and hence the need to consider them as a hierarchical system. Thus, the problem becomes a problem of (i) allocation of the budget among the different hierarchies; (ii) facilities in each hierarchy; and (iii) allocating customers to facilities (Daskin, 1995), and can be solved through so-called Hierarchical Facility Location Models (HFLM).

In a hierarchical system of installations, demand naturally divides into two levels: the first one of procedures with lower risk and lower aggregate structural cost, and the second of procedures with greater complexity and with high structural value, as explored in Galvão et al. (2002). It is often useful to classify systems by the way services are offered and by the region for which services are provided. Service levels are numbered from 1 to $k$ : level 1 is the lowest service or facility (for example, a health post) and level $k$ is the highest level (general hospital).

One of the most well-known hierarchical problems, and what will be addressed in this paper, is the Median-Based Hierarchical Location Problem. This class of models is also known as pq-median, and is a variant of the single-level $\mathrm{p}$-median model. The model in this system, in which a level $k$ facility offers level $k$ services and all lower ones to all vertices, has the following mathematical modeling for the globally inclusive problem, according to Narula (1986) classification:

$$
\begin{aligned}
& \text { Parameters } \\
& I=\text { set of all cities that must be met } \\
& J=\text { set of all candidate cities to receive a facility } \\
& d_{i j}=\text { distance matrix, with } d_{i i}=0 \forall i \in I \\
& K=\text { servicelevels } \\
& h_{i k}=\text { demand for level } k \in K \text { at vertex } i \in I \\
& P_{k}=\text { number of facilities of level } k \in K \text { to be allocated }
\end{aligned}
$$

Decision variables

$$
\begin{aligned}
& y_{j k}=\left\{\begin{array}{c}
\text { lif a facility of level } k \in K \text { is allocated at vertex } j \in J \\
\text { 0otherwise }
\end{array}\right. \\
& x_{i j k}=\left\{\begin{array}{c}
\text { 1if the demand of the vertex } i \in \text { I by thelevel } k \in K \text { is satisfied by the } \\
\text { facilitylocated at the vertex } j \in J \\
\text { 0otherwise }
\end{array}\right.
\end{aligned}
$$

Objective funcion

$$
\operatorname{Min} \sum_{i \in I} \sum_{j \in J} \sum_{k \in K} h_{i k} d_{i j} X_{i j k}
$$

Subject to

$$
\begin{array}{r}
\sum_{j \in J} X_{i j k}=1 \quad \forall i \in I ; k \in K \\
\sum_{j \in J} Y_{j k}=P_{k} \quad \forall k \in K
\end{array}
$$




$$
\begin{gathered}
X_{i j k} \leq \sum_{g=k}^{m} Y_{j g} \quad \forall i \in I ; j \in J ; k \in K \\
\sum_{k \in K} Y_{j k} \leq 1 \quad \forall j \in J \\
Y_{j k} \in\{0,1\} \quad \forall j \in J ; k \in K \\
X_{i j k} \in\{0,1\} \quad \forall i \in I ; j \in J ; k \in K
\end{gathered}
$$

The objective function [1] minimizes the demand-weighted distance covered at each point. Restriction [2] stipulates that all local demand types must be assigned to some facility. Restriction [3] determines the total number $P_{k}$ of installations type $k \in K$ to be located. The restrictions [4] are binding constraints, they establish that the demands for the $k \in K$ service that originate at node $i \in I$ can not be assigned to an installation at node $j \in J$, if it is not a facility of type $k \in K$ or higher. In the case of the healthcare system, this restriction defines that a procedure of high complexity can not be attributed to a basic unit, for example only units of compatible complexity. In this formulation, constraints [5] require that a maximum of one installation be is assigned to a vertex $j \in J$. The constraints [6] and [7] refer to the binary nature of the decision variables.

\section{The case developed}

The health system, including the area of oncology, already in its foundations, has a hierarchical structure of two or more levels, varying with the species and complexity of the procedure and, consequently, the structure and capacity of the facility. In this way, the public service facilities in this area are divided naturally into two levels: the first of the lowest risk procedures and the lowest aggregate structural cost, and the second of procedures with greater complexity and with high structural cost.

This division also guarantees us to separate the demand for services from the two levels, which, if executed according to plan, can bring significant gains in the quality of the services rendered, which in the oncology is primordial to the user generally debilitated by the aggressive symptoms of the disease. That is why the location of the facilities is such an important decision for health managers. When financial resources for network expansion are scarce, greater is the need for substantiated decision-making. This situation is faced by the state of Rio de Janeiro, which in addition to an installed network already deficient, goes through financial difficulties that may make it difficult or even impossible to construct new units.

With the hope that the scenario will reverse, this paper will present a proposal for a facility location model that can be used by the organs responsible for strategic public health decisions in the ERJ to obtain the exact locations of future cancer care facilities in order to optimize the access of the population.

In this application, a total of 46 cities were selected based on the shortage of service in the region. Another crucial factor to choose was the fact that demographic density data indicates that the disparity of the population of the metropolitan and the interior regions could disturb the results and bring a result that does not fit to the reality.

\section{Proposed model}

The construction of new public healthcare units allows us to consider two different possibilities in terms of optimization: to idealize a network that optimizes the use of the state's financial resources, to minimize costs to public coffers, while ensuring coverage of all demand; or optimize the population's access to the service, improving quality by minimizing the distance traveled by users to the service points. The first possibility would be easily adapted to the Full Coverage HFLM, while the second one to the Globally Inclusive Median-Based HFLM, also called pq-median.

Both models would respect, in a comparable way, the basic guideline of the universalization in SUS, one of the doctrinal principles of the Brazilian state health policy, in which all Brazilian citizens have the right to access to health services and actions. However, as far as service completeness/integrality is concerned, differences between models become clearer.

According to the Fiocruz's platform Pense SUS, the integrality in health means that the care system must be prepared to listen to the user, understand it inserted in its social context and, from there, meet the demands 
and needs of this person. looking from the perspective of users, integral action in health is associated with respectful, dignified treatment, with quality and hosting.

Therefore, reworking the analysis of the adaptation of the two highlighted models, now with the perspective of the humanization of care that we can say be foreseen in the fundamental principles of the SUS through the interpretation of the concept of integrality, the complete coverage model is negligent, since it covers the aspect of distance limiting the maximum acceptable but not as object of improvement. In this way, we conclude that in this application, the maximum coverage model would not prioritize quality or patient's satisfaction.

On the other hand, the pq-median already presents in its objective the minimization of the distance traveled by the user weighted by the demand for the service, showing that it adheres not only to the concept of integrality, but also to that of equity, in which the right to health goes through social differentiations and recognizes that everyone needs attention, but not necessarily the same services, and therefore where there is greater need, there must be more investment (Brasil, 2014). These evidences make the model the best candidate for use in the system proposed in this work.

However, it can not be ignored that limiting the distance traveled to a maximum value, present in the models of coverage, could benefit the construction of the network of installations. For the user, this would imply a guarantee that, regardless of the number of units allocated, he will have a unit which he must address in case of need and this unit will be within acceptable distance of his locality. This would imply both the improvement of the user's planning in their locomotion, when planning the fleets of ambulances, which will have a more precise radius of care, and the public vehicles designated to transport users of the health network, usually provided by the city halls for the transport of users that will be served in other municipalities. Therefore, this benefit was added to pq-median with the addition of the restriction of the distance between the allocated facility and the demands assigned to it, where the maximum distance is an exogenous variable.

Another hypothesis raised during the choice of the model was that the weighted demand does not imply that only populous cities would receive facilities, since the algorithm would sweep all cities and thus consider regions and not only isolated nodes. And this brings us to a possibility that needs to be questioned: Are all cities able to receive facilities of both levels? The answer apperars to be negative: there are cities with a very small population, less than 20.000 inhabitants. The population of a city by itself should not be an obstacle to the allocation, however, indirect factors such as urban structure, waste treatment, sanitary infrastructure, public mobility, supply of skilled labor or the structure necessary to receive workers and users of other cities are obstacles that depend on public investment policies from other sectors of society, and are not within reach of the health sector.

It made necessary to select the candidate cities and the eligibility parameter was created. The implementation of this idea in the model starts from the addition of a restriction determining that facilities can be allocated only to eligible cities, where eligibility was also used as an exogenous variable. In this way, the model constructed and applied in this study has the decision variables, objective and constraints presented below. As can be seen throughout this section, the construction of the model was carried out with the characteristic data of this application, in the SUS oncology, using exogenous parameters always as possible, aiming at the use of the mathematical and computational model in other approaches or public policies.

Parameters

$$
\begin{aligned}
& I=\text { set of all cities that must be met } \\
& J=\text { set of all candidate cities to receive a facility } \\
& K=\text { service levels } \\
& n=\text { number of demand points. } I=\{1, \cdots, n\} \\
& m=\text { number of candidates to receive a facility. } J=\{1, \cdots, m\} \\
& s=\text { number of network levels. } K=\{1, \cdots, s\} \\
& d_{i j}=\text { distance matrix, with } d_{i i}=0 \forall i \in I \\
& \text { dem }_{i k}=\text { demand for level } k \in K \text { at vertex } i \in I
\end{aligned}
$$


dmax $_{k}=$ maximum acceptable distance between a facility of level kò $\mathrm{K}$

and their demand.

$z_{j k}=\left\{\begin{array}{c}\text { Iif city } j \in J \text { is eligibletoreceive a facility of level } k \in K \\ \text { 0otherwise }\end{array}\right.$

$P_{k}=$ number of facilities of level $k \in K$ to be allocated

Decision variables

$y_{j k}=\left\{\begin{array}{c}\text { lif a facility of level } k \in K \text { is allocated at vertex } j \in J \\ \text { 0otherwise }\end{array}\right.$

$x_{i j k}=\left\{\begin{array}{c}\text { lif the demand of the vertex } i \in I \text { bythelevel } k \in K \text { is satisfied by the } \\ \text { facilitylocated at the vertex } j \in J \\ \text { Ootherwise }\end{array}\right.$

Objective function

$$
\operatorname{Min} \sum_{i \in I} \sum_{j \in J \in} \sum_{k \in K} \operatorname{dem}_{i k} d_{i j} x_{i j k}
$$

Subject to

$$
\begin{gathered}
\sum_{j \in J} x_{i j k}=1 \quad \forall i \in I ; k \in K \\
z_{j k} \geq y_{j k} \quad \forall j \in J ; k \in K \\
\sum_{j \in J} y_{j k}=P_{k} \quad \forall k \in K \\
x_{i j k} \leq \sum_{g=k}^{s} y_{j g} \quad \forall i \in I ; j \in J ; k \in K \\
d m a x_{k} \geq d_{i j} x_{i j k} \quad \forall i \in I ; j \in J ; k \in K \\
\sum_{k \in K} y_{j k} \leq 1 \quad \forall j \in J \\
x_{i j k} \in\{0,1\} \quad \forall i \in I ; j \in J ; k \in K \\
y_{j k} \in\{0,1\} \quad \forall j \in J ; k \in K
\end{gathered}
$$

The Equation [8] minimizes the distance between the demand and the installation which will be designated, weighted by demand. Restriction [9] determines that the demands of each city should be met by an installation of the appropriate level. Restriction [10] ensures that facilities will be allocated only in eligible cities, and [11] defines the exact number $P$ of installations to be allocated at each level. [12] determines that the demand for a vertex at service level $k$ can only be met by an installation if the level is equal to or greater than $k$. [13] ensures that the distance from the demand by one level to the facility designated to it will be less than the maximum feasible distance for each level. Function [14] determines that a facility can be allocated in each city. [15] and [16] refer to the binary nature of the decision variables.

With the mathematical model defined, it can be classified based on the parameters which are relevant to this application listed in Farahani et al. (2014), according to Table 2. 


\begin{tabular}{ccc}
\hline Flow pattern & SF & Single-flow \\
\hline Flow pattern & Ref & Referral \\
Service availibility & $\mathrm{N}$ & Nested \\
Objevtive funcion & $\mathrm{M}$ & Median \\
Network levels & $\mathrm{k}$ & General case \\
Facilities & $\mathrm{Ex}$ & Exogenous \\
Capacity & $\mathrm{U}$ & Unlimited \\
Application & $\mathrm{HC}$ & Health care \\
\hline
\end{tabular}

In this application, the model has 2,208 binary decision variables and 8,696 linear constraints, which is, therefore, a pure binary programming problem.

\section{Data collection and application}

The $46 \times 46$ matrix of distances between all cities were obtained using the Distance Matrix tool of Google Maps $\mathrm{API}^{\circledR}$. Matrix elements refer to the distance in kilometers of the route between the centroids of each pair of cities.

Level 1 facilities will offer the services of lower complexity, where there is no need for long-term hospitalization or high-risk procedures and facilities require less investment, while level 2 facilities would be responsible for high complexity interventions in addition to lower level services, equipped with a surgical center and intensive care units, in the case of high-cost facilities. Table 3 below shows the result of this division and the average of the demand for these treatments presented individually and in the set of services of each level.

Table 3. Treatments correspondents to each level of service and the proportion of the demand.

\begin{tabular}{clcccc}
\hline \multicolumn{1}{c}{ Procedure } & Cases & $\%$ (Cases) & $\%$ (Level) & Absolute $\%$ \\
\hline \multirow{2}{*}{ Level 1 } & Hormone Therapy & 14,603 & $8.52 \%$ & $71.95 \%$ & $59.19 \%$ \\
& Chemotherapy & 55,204 & $33.21 \%$ & & \\
& Radiotherapy & 44,757 & $26.20 \%$ & & $40.81 \%$ \\
& Others & 6,978 & $4.02 \%$ & $49.60 \%$ & \\
\hline
\end{tabular}

Source: Based on Integrador RHC data in INCA (Instituto Nacional de Câncer José Alencar Gomes da Silva, 2018a).

It is worth to remark that the proportion of demand for level 2 used in the methodological application refers only to the exclusive services of this level, it means high risk services, even if it is a successively inclusive model. By approximation, the proportions 60\% and 40\% were used, for levels 1 and 2, respectively.

The demand for the service in this application refers to the number of patients who seek the different oncological treatments by SUS in each city. However, this information was not found with the desired reliability in the official databases made available to the public. As an alternative to this problem, instead of using the proportion of the levels over the average annual number of registered cases, it will be applied directly to the population of each municipality, obtained from the estimation made by the Instituto Brasileiro de Geografia e Estatística (2018) for the year 2017, the most recent. This application can be performed without damage to the quality of the results, mathematically, since the demand works as weights attributed to the vertices of the model, only in comparative character, and this was one of the reasons for the facilities to be considered with unlimited capacity.

The eligibility criterion is qualitative and permeates the social and economic aspects of the candidate cities. These determining factors are beyond the author's technical decision-making ability, as well as the collection of concrete and updated data from various sectors, which should be analyzed on a case-by-case basis. As this type of analysis is outside the scope of this study, the parameter was linked only to the resident population, since, in essence, it should reflect the evolution of socioeconomic factors in the municipality.

The lower bound of the resident population will be different for different levels of service. It was considered reasonable for level 1 to require at least 20,000 people, and for level 2 40,000 people. This cut resulted in 28 cities eligible to receive installation of level 1 and 14 to level 2. This parameter is exogenous to the model and can be changed in the database itself for the reproduction in other applications. 
For the determination of maximum distance, two aspects of the spatial configuration were considered: the longest distance between an ineligible city and a candidate city of the level corresponding to the distance in question, and the distance allowed considering only the guarantee of access quality. When the former is less than the latter, it means that there may be excess facilities in a given region and they will be underutilized. When the second one is smaller than the first, it means that if you choose to guarantee quality, some city will be left unattended and the model will not give any response, since it is programmed for the universality of the service. With this, the conclusion is that the greatest distance must prevail.

In this application, the longest distance between an ineligible city and a candidate city prevailed. The city of Carmo, not eligible, is approximately $51.7 \mathrm{~km}$ away from Cordeiro, the nearest candidate city on level 1. The ineligible city of Santa Maria Magdalena is approximately $91.9 \mathrm{~km}$ from Nova Friburgo, the nearest candidate city on level 2. These exact values were not used in the model, as this would imply the mandatory allocation of a level 1 facility in Cordeiro and a level 2 facility in Nova Friburgo. And because the maximum distance parameter is very dependent on the eligibility, which is subjective, it was decided to use the illustrative values of $[60,110]$ kilometers for the levels [1,2], in order to give greater flexibility to the model and to test its effectiveness.

The number of facilities of each level to be allocated was determined arbitrarily, since it involves budgetary aspects of the State Government together with the Municipalities. Thus, six different configurations were established, arranged in Table 4 of the following scenarios, whose results will go through a sensitivity analysis to analyze the behavior of the results with the variation of this parameter and also to mitigate the hypothesis of certainty in the coefficients.

Table 4. Configuration of the scenarios as to the number of Installations to be allocated in each level.

\begin{tabular}{ccc}
\hline Scenarios & \multicolumn{2}{c}{ Number of Facilities } \\
\cline { 1 - 3 } \cline { 3 - 3 } \cline { 3 - 3 } \cline { 3 - 3 } & Level 1 & Level 2 \\
2 & 5 & 4 \\
3 & 10 & 4 \\
4 & 12 & 5 \\
5 & 14 & 6 \\
6 & 16 & 7 \\
\hline
\end{tabular}

\section{Results and discussion}

The model was implemented computationally in the IBM ILOG CPLEX Optimization Studio ${ }^{\circledR}$, in its version 12.7.1. The model, after testing, was submitted to the 6 scenarios previously presented. The binary results determined by the model were tabulated, so that it is possible to visualize which cities would receive facilities of each level, and which cities each one of them would be responsible for attending. In order to visualize spatially, the information of the tables was arranged in maps of the study region, with Figure 1 for services of level 1 and Figure 2 of those of level 2. In the figures, the yellow dots represent the Installations of level 1, whereas the red ones, level 2. The color groupings signal the demand groups, that is, the cities that will be served by the same facility, which by definition is unique, allocated in that region.

It can be seen in the figure that the model allocated facilities uniformly and dispersed throughout the study territory and always centralized in the demand groups, an expected result due to the natural characteristic of the median based models. However, it is not possible to visually assess whether the model prioritized the parameter maximum distance versus demand, the objective function weighting factor, which is mathematically expected. Apparently, this occurred due to the high number of units installed for an analysis with this detailing, in a small region. For this reason, it is expected that the assessment in level 2 installations will be more conclusive in this regard.

It is possible to notice in the mapping that the increase of the parameter P reduced the number of cities served by a same installation and the groups of demand have become, in general, smaller and cities have emerged totally independent and serve only themselves. Given the application in the public sector, and in the case of facilities of medium complexity and lower cost in relation to services level 2, this characteristic is fundamental to make possible the concept of SUS hierarchy. A single city responsible for serving users from many neighboring cities will be burdened not only in the health service, but also in other sectors of the municipal organization such as hospital waste, sanitation and vehicular traffic, and political and budgetary issues may pose obstacles 


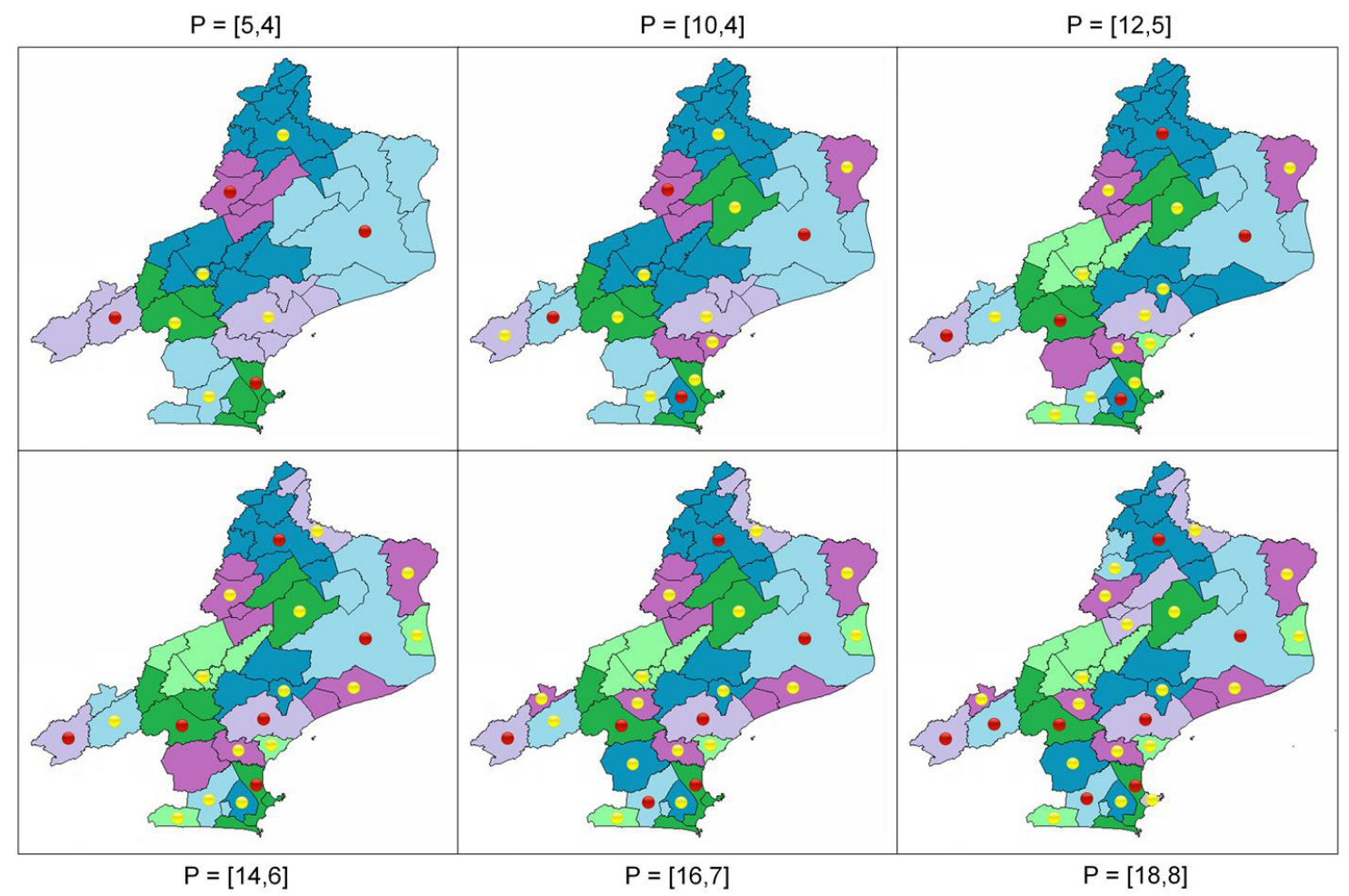

Figure 1. Facilities location that offers level 1 services and the respective attended region.

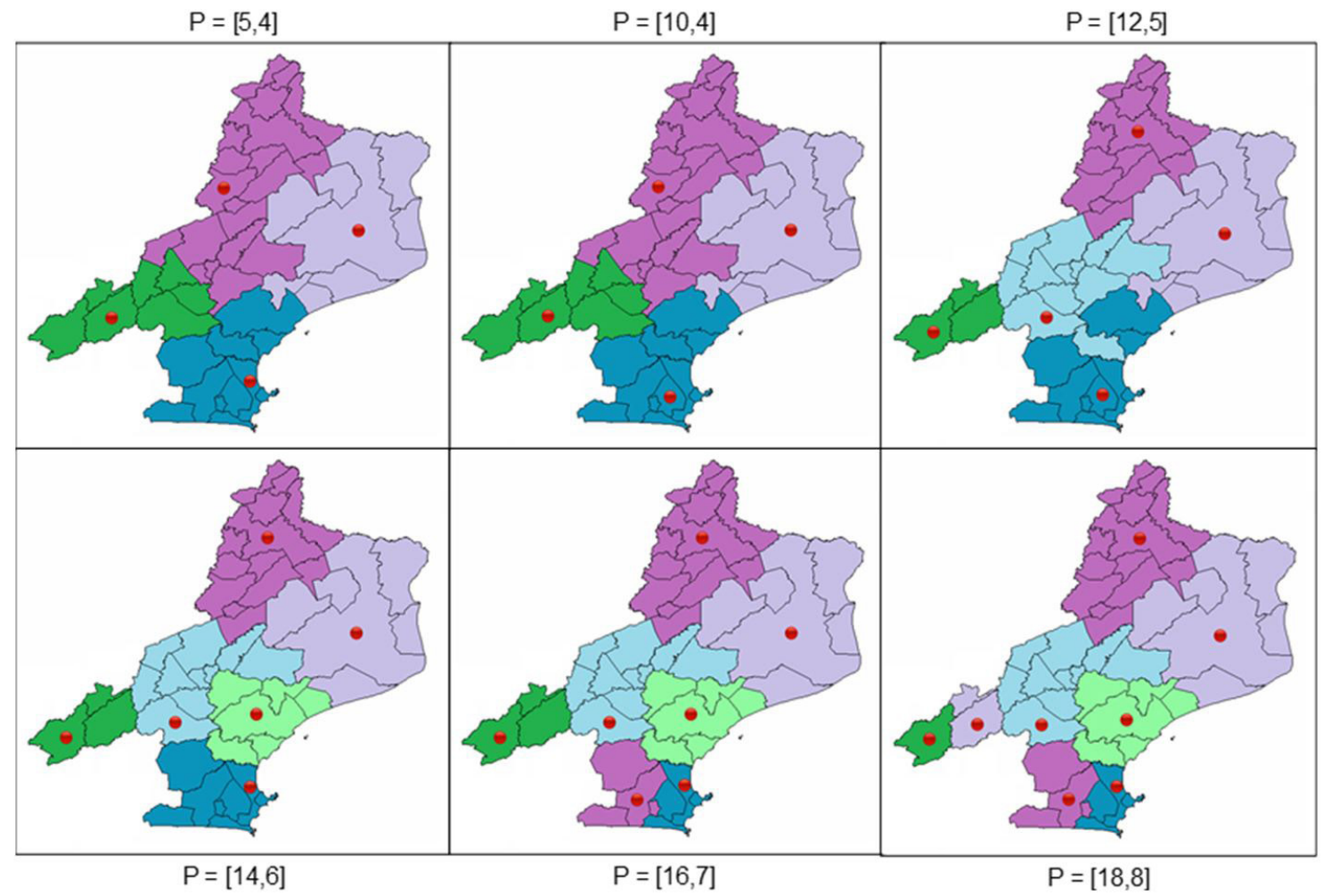

Figure 2. Level 2 facilities location and the respective attended region. 
to the deployment and the unit. Therefore, it is desirable (ideal) that demand groups be composed of a single city, and in the model proposal, the largest groups remaining in scenario 6 (of higher P values) are those in which there are many ineligible cities in the regions, showing sensitivity to this need of the system.

In the compilation of maps of level 2 installations, the prioritization of the maximum distance parameter and therefore the centrality of the installations in its group is evident. In scenarios 1 and 2, in the purple and green groups, it is noted that the installation was not located in the most populous cities that minimize the median (Itaperuna and Petrópolis), but in the most populous cities that are able to meet the distance requirement (Santo Antônio de Pádua and Teresópolis).

Another interesting observation was regarding the division of the groups by increasing the value of $\mathrm{P}$. It can be observed that from scenario 4 to scenario 5 the division of the blue demand group occurred in two, with no change in the neighboring groups. The same happened from scenario 5 to 6 with the dark green demand group. This shows that the model has the necessary sensitivity so that it can be determined when the system becomes saturated. Even though from the user's point of view the greater the number of facilities the better, reality requires that the network of facilities be also constructed in a financially responsible manner, since there are budget limits for any public investment.

By analyzing quantitatively, the scenarios obtained revealed that the higher the number of installations in each level lower is the average distance traveled by the user. In Table 5 is presented the sensitivity of the model applied to the different configurations regarding the distance traveled.

Table 5. Results for maximum and average distances traveled for each level.

\begin{tabular}{cccccc}
\hline & \multicolumn{3}{c}{ Level 1 } & & \multicolumn{2}{c}{ Level 2 } \\
\cline { 2 - 3 } \cline { 5 - 6 } & Max $(\mathrm{km})$ & Mean $(\mathrm{km})$ & & Max $(\mathrm{km})$ & Mean $(\mathrm{km})$ \\
\hline Scenario 1 & 59.280 & 29.740 & & 109.138 & 57.761 \\
Scenario 2 & 57.936 & 24.029 & & 109.138 & 56.410 \\
Scenario 3 & 51.764 & 20.502 & & 91.876 & 48.598 \\
Scenario 4 & 51.692 & 17.700 & & 91.876 & 45.134 \\
Scenario 5 & 51.692 & 15.304 & & 91.876 & 42.316 \\
Scenario 6 & 51.692 & 13.410 & & 91.876 & 40.454 \\
\hline
\end{tabular}

The variation of data was captured for the parameters maximum distance between a user and the installation that covers it, and the average distance traveled between users and the corresponding installations, shown in Figure 3.

\section{Mean Distance Traveled (km)}



Figure 3. Mean distance traveled by users in each level.

With the proposed variation of the parameter $\mathrm{P}$, the maximum distance traveled by a user decreased $12.8 \%$ for service level 1 and 15.8\% for level 2. The average distance presented a substantial reduction of 66\% for level 1 and 29.9\% for level 2.

An interesting fact can contribute to the analysis and understanding of the importance of results achieved. According to INCA, there are eight oncology care units in the region that is the object of this study, which brings the scenario 1, with nine, closer to the actual configuration in number of facilities, although not in relation to the spacial distribution of them (eight units are allocated in five cities and only in Campos dos Goytacazes there are three). This indicates that if the goal of implementing a network such as scenario 6 is adopted, the distance traveled by all patients would fall one-third at level 1 and more than half at level 2, on average. 


\section{Conclusion}

The realization of this study made it possible to draw some conclusions about the network location models and oncological care infrastructure within the ERJ. In the bibliographic review it was possible to review some concepts and characteristics of the Operational Research allowing the choice of the most appropriate model to be implemented computationally. During the research it was necessary to delimit the geographic space of the study to the interior of the state. This choice was made based on the natural demographic limitations imposed on the model. The choice of the public service and the hierarchical model based on globally inclusive median not qualified was due to the characteristics of the Unified Health System and its exemplary doctrinal and organizational principles provided by the legislation. Nonetheless, the choice of the oncology area was due to the current context of increasing incidence and mortality due to the disease and the precariousness of the care received by the population. The fact that the health in the ERJ goes through a state of calamity, even being such a basic citizen's right, was a strong motivator in the elaboration of this study. With the intention of collaborating for a more precise health management in its actions, not only effective but efficient for the population, the hierarchical pq-median model was used to optimize the allocation of facilities.

The results generated in the CPLEX shown the relation between the number of facilities and the distance covered by cancer patients from SUS. It was observed that the higher the number of service points of each level, the lower the user's movement to the service. The reality of the service offer in the delimited region compares to scenario 1, where $P$ assumes the lowest possible execution values of the model in the set parameters, 5 for the first level and 4 for the second. In fact, the units already installed add up to one less than the minimum for the model, which illustrates the magnitude of the service deficiency. Given the facts, it is advantageous to use the model chosen to optimize the allocation of health facilities and any other system with the same characteristics, as other public initiatives. It is worth emphasizing that the model will never replace the health manager. On the contrary, the model improves its ability to analyze and make decisions.

For future related works it is suggested to include in the scope a step of collecting actual data, if the data used is not yet properly consolidated. After all, the improvement of information control can not be expected to happen in the short term, given the state of deficiency it is in. This would enable a more accurate and realistic result.

Take data on the capacity of health facilities so that the trained model can be implemented. In this way it would be possible to obtain parameters related to operating costs other than unit installation costs, a factor that was not addressed in this study due to lack of data, but which is a factor of extreme political and technical importance, is a determining factor in the choice of parameter $\mathrm{P}$, for example. Decrease the scale of the geographical space. With the model enabled on the scale not of cities, but of zones or neighborhoods, it would be possible to better understand the needs of the population and to locate with much more precision and quality the facilities.

\section{Limitations and future research}

This application needed public data available on government agency websites. As explained above, the dubious quality of these data, when they existed, made it prudent to use parameters parallel to the information sought, then illustrative values, and to make considerations that would not be necessary if there were access to reliable real data.

Therefore, it should be emphasized that the results obtained do not suggest any immediate action to build any health unit. The research suggests, rather, that the tested model be used as a tool to support decision making, executed from concrete data. The research was limited in this work to show that the model is efficient in locating facilities of a successively inclusive hierarchical system, given the parameter P. It was not sought to determine an exact value of facilities to be constructed, since this decision competes with very knowledge more specific in the social and health sciences, than in mathematical sciences or information technology.

It is important to highlight that the proposed model can be applied in other contexts, whether applied to the public sector or to the private sector. In the public sector, the model can be adjusted and adapted to define the location of teaching units, hospitals, health clinics, among other possibilities. For the private sector, the model can be adapted, by means of a specific context, to define the location of units to be installed (distribution center, collection points for reverse logistics, and other applications). It is important to highlight that for these cases. It is fundamental to analyze the model and make pertinent adaptations according to each context. 
Another point worth mentioning in terms of future research is the possibility of refining the model considering the location of existing installations and capture the stochastic aspects of demand over time. However, in the latter case, the importance of reliable data on the actual demand and how it varies over time is highlighted.

\section{Acknowledgements}

This study was financed in part by the Coordenação de Aperfeiçoamento de Pessoal de Nível Superior - Brasil (CAPES) - Finance Code 001.

\section{References}

Ahmadi-Javid, A., Seyedi, P., \& Syam, S. S. (2017). A survey of healthcare facility location. Computers \& Operations Research, 79, 223263. http://dx.doi.org/10.1016/j.cor.2016.05.018.

American Cancer Society. (2018). Text alternative for rising global cancer epidemic. Retrieved in 2019, March 31, from https://www. cancer.org/research/infographics-gallery/rising-global-cancer-epidemic/rising-global-cancer-epidemic-text-alternative.html

Arenales, M. (2007). Pesquisa operacional. Rio de Janeiro: Elsevier.

Ballou, R. H. (2001). Gerenciamento da cadeia de suprimentos: planejamento, organização e logística empresarial (4. ed.). Porto Alegre: Bookman.

Belfiore, P., \& Fávero, L. P. (2013). Pesquisa operacional para cursos de Engenharia. Rio de Janeiro: Elsevier.

Boonmee, C., Arimura, M., \& Asada, T. (2017). Facility location optimization model for emergency humanitarian logistics. International Journal of Disaster Risk Reduction, 24, 485-498. http://dx.doi.org/10.1016/j.ijdrr.2017.01.017.

Brasil. (1988, Outubro 5). Constituição da República Federativa do Brasil de 1988. Diário Oficial da República Federativa do Brasil.

Brasil, Ministério da Saúde. (2014). Protocolos clínicos e diretrizes terapêuticas em Oncologia. Brasília: Secretaria de Atenção à Saúde.

Daskin, M. (1995). Network and discrete location: models, algorithms and applications. New York: John Wiley and Sons Inc. http:// dx.doi.org/10.1002/9781118032343.

Daskin, M., \& Dean, L. (2004). Location of health care facilities. In F. Sainfort, M. Brandeau \& W. Pierskalla (Eds.), Handbook of OR/ MS in health care: a handbook of methods and applications (pp. 43-76). Norwell: Kluwer Academic Publishing.

Drezner, Z., \& Hamacher, H. W. (2002). Facility location: applications and theory. New York: Springer-Verlag. http://dx.doi.org/10.1007/9783-642-56082-8.

Farahani, R., Hekmatfar, M., Fahimnia, B., \& Kazemzadeh, N. (2014). Hierarchical facility location problem: models, classifications, techniques, and applications. Computers \& Industrial Engineering, 68, 104-117. http://dx.doi.org/10.1016/j.cie.2013.12.005.

Ford, M., \& Mitchell, M. (2000). Epidemiologia do câncer. In K. L. Boyer (Ed.), Oncologia na clínica geral (pp. 3-20). Rio de Janeiro: Guanabara.

Galvão, R., Espejo, L., \& Boffey, B. (2002). A hierarchical model for the location of perinatal facilities in the municipality of Rio de Janeiro. European Journal of Operational Research, 138(3), 495-517. http://dx.doi.org/10.1016/S0377-2217(01)00172-2.

Instituto Brasileiro de Geografia e Estatística - IBGE. (2018, Abril 30). Population Estimates. Retrieved in 2019, March 31, from https:// www.ibge.gov.br/estatisticas-novoportal/sociais/populacao/9103-estimativas-de-populacao.html?=\&t=0-que-e

Instituto Nacional de Câncer José Alencar Gomes da Silva - INCA. (2017). Estimativa 2018: incidência de câncer no Brasil. Rio de Janeiro: Coordenação de Prevenção e Vigilância - INCA.

Instituto Nacional de Câncer José Alencar Gomes da Silva - INCA. (2018a, June 28). Integrador RHC. Retrieved in 2019, March 31, from https://irhc.inca.gov.br/RHCNet/visualizaTabNetExterno.action

Instituto Nacional de Câncer José Alencar Gomes da Silva - INCA. (2018b, June 27). Registros de câncer de base populacional. Retrieved in 2019, March 31, from http://www2.inca.gov.br/wps/wcm/connect/estatisticas/site/home/rcbp/

Leiras, A., González-Calderón, C. A., Brito, 1., Jr., Villa, S., \& Yoshizaki, H. (Eds.). (2019). Operations Management for Social Good: 2018 POMS International Conference in Rio. USA: Springer.

Lisboa, L. (2014). Tratamento de radioterapia em pacientes oncológicos. Vitória: Faculdade Católica Salesiana do Espírito Santo.

Narula, S. (1986). Minisum hierarchical location-allocation problems on a network: a survey. Annals of Operations Research, 6(8), 257272. http://dx.doi.org/10.1007/BF02023745.

Ortiz-Astorquiza, C., Contreras, 1., \& Laporte, G. (2018). Multi-level facility location problems. European Journal of Operational Research, 267(3), 791-805. http://dx.doi.org/10.1016/j.ejor.2017.10.019.

Ruth, R. J. (1981). A mixed integer programming model for regional planning of a hospital patient service. Management Science, 27(5), 15261537. http://dx.doi.org/10.1287/mnsc.27.5.521.

Toregas, C., Swain, R., ReVelle, C., \& Bergman, L. (1971). The location of emergency service facilities. Operations Research, 19(6), 13631373. http://dx.doi.org/10.1287/opre.19.6.1363. 